\section{Citizens' Perceptions of \\ Environmental Noise - A Case \\ Study}

Gl_Forum 2018, Issue.1

Page: 126 - 134

Full Paper

Corresponding Author:

podor.andrea@amk.uni-obuda.hu

DOI: 10.1553/giscience2018_01_s126

\author{
Andrea Pődörl and Dorina Borsföldi-Nagy² \\ 'Óbuda University Székesfehérvár, Hungary \\ ${ }^{2}$ Chartered Surveyor
}

\begin{abstract}
In this study, the authors used an online survey to investigate the perception of noise pollution by the citizens of Szombathely in Hungary. The datasets were compared to field measurements taken with a sound-level meter, and a smartphone using a free noisemeasurement app. On the whole, the participants identified the main roads and transport hubs as the most polluted areas, and parks and green spaces as the least polluted ones. Our measurements confirm that citizens are well aware of noise pollution in the city, although in some cases we found slight differences between their subjective perceptions and the actuality.
\end{abstract}

\title{
Keywords:
}

noise mapping, smartphone noise measurement, digital sketch maps

\section{Introduction}

Most citizens are well aware of environmental problems, although in some cases they are unable to estimate the extent of environmental noise exposure (Becker et al., 2013). In an earlier survey, the authors had used a web application to gain information about groups' and individuals' spatial fears of crime (Pődör \& Dobos, 2014). They found a significant difference between ground-truth data and citizens' perceptions of socio-spatial processes.

We were interested in whether we could detect similar differences in the case of environmental pollution, whether citizens have a false idea about their environment, or whether their concept is closer to reality than in the case of sociological data. As noise pollution is one of the principle (and emerging) environmental problems in urban territories (EEA, 2013), we concentrated our examination on environmental noise exposure. According to the literature, assessment is subjective in the case of noise (Becker et al., 2013); it depends on personal sensitivity, age, health status, and the relationship to the noise source (Bencsics, 2006).

The use of crowdsourced data collection for environmental noise exposure has already been examined in terms of its feasibility for updating and creating noise maps (Pődör et al., 2015). 
We used sketch maps for a survey, as they have recently been used successfully in participatory and subjective geographic data systems (Boschmann, \& Cubbon, 2014) to collect unique spatial information about individual encounters.

After the evaluation of the results of the online survey, we carried out control measurements in the field. The increased accessibility of location-enabled smartphones with a range of advanced sensors allows information to be obtained more productively. Although usergenerated noise measurements cannot replace professional surveys, they can provide extra information relevant to strategic noise mapping and monitoring (Pődör \& Révész, 2014).

Our hypothesis was that citizens would not be able to define all areas with high noise pollution within the city. After the online survey, we designated the main noisiest and quietest locations identified by the respondents. We carried out control measurements both there and at other locations to examine the general level of noise pollution in the city.

\section{The study area}

Szombathely is a typical western Hungarian city. It is situated close to the Austrian border and is the 10th largest city in Hungary, with around 80,000 inhabitants. There are four main approach roads for the city, which are sources of relatively high noise pollution. The urban development strategy of Szombathely identifies 18 urban zones in the city (Figure1). In the middle of the city, we find the historical centre (see Figure 1 - zone 1). Because of noise pollution, private transport is partially banned here and has been rerouted to nearby streets, causing increased noise pollution there. Local people have complained about this. The bus and train stations form a local transport centre (1).

The western part of the city comprises mainly residential zones (8-11); the eastern part, near the city's four main approach roads, includes mostly industrial areas (16). Constant noise exposure can be detected in the industrial zone, due to the high number of incoming and outgoing lorries and employees' private transport.

A residential area virtually encircles the city centre (2). Green spaces are also an important part of the city's structure. These are situated mostly in the western part, in zones 4 and 11 (Szombathely Transport Consortium, 2015). 


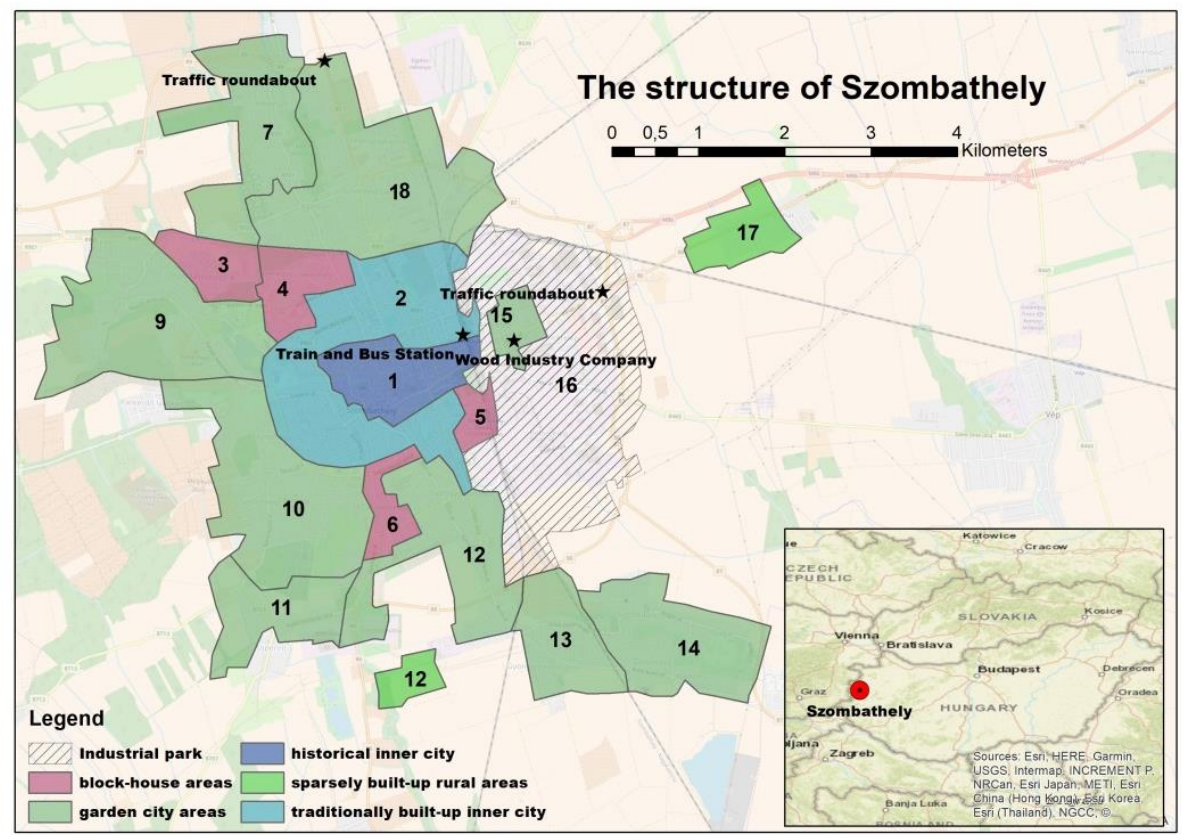

Figure 1: The urban zones of Szombathely

The most critical problem of noise pollution is caused by a wood industry company (one of the largest in Central-Eastern Europe in zone 15), which is involved in constant disputes with the citizens of the residential areas nearby.

\section{Methodology}

Stanley Milgram (1992) developed a free-recall technique in which respondents had to draw their mental maps on a blank sheet of paper. The problem with this method is that different people see the same places differently, so it is hard to compare these maps with each other, and it is difficult to extract information from them. Recently, various data collection techniques have been developed in mental mapping (Pánek, 2016). These include purely quantitative data collection methods that use surveys; purely qualitative non-drawing-based ones that use interviews; free-recall data collection techniques based on freely drawn maps; oriented recall map drawing with an interview; and data collection methods based on existing maps and images (Letenyei, 2005).

Many studies have used mental and sketch maps (Boschmann \& Cubbon, 2014) to interpret an environment qualitatively in terms of feelings such as fear, desire and stress. Mental maps are tools for behavioural geographers to comprehend human behaviours based on people's impressions of their spatial environment. Sketch maps have been utilised within participatory and qualitative geographic information systems to describe spatial stories of groups or individuals (Boschmann \& Cubbon, 2014). 


\section{The data acquisition application}

In our study, a web application was used for an online survey. The webpage is available at http://zaj.amk.uni-obuda.hu/. The application is based on the oriented recall map drawing procedure and is designed for online use and mobile phone applications. For the base map, we chose Google Maps, which is commonly used by Hungarian citizens. To promote the online survey and reach potential participants, we used mainly social media (Facebook, Viber). The survey is consequently skewed, because respondents had to have online and map-reading competencies (use of social media and familiarity with Google Maps). The survey should therefore be considered as a model experiment. To calculate the results, we covered the area with a grid (200 metres x 200 metres) and used basic GIS calculating methods.

The webpage itself uses the Google native web API; the drawing function is available through Drawing Manager; respondents can use the webpage without the need to register. There is a short form where participants give their postcode, age, gender and usual mode of transport, because according to Bencsics (2006) these facts also influence the perception of noise. After filling in their personal data, the user finds a short explanation of how to use the map. Following instructions, they can define noisy and quiet places using a polygon tool. The participants were asked to delineate a minimum of 5 noisy and 5 quiet areas on the map.

\section{Field measurements}

With the help of the online survey, we designed a field survey, marking the main measurement points indicated by respondents.

We tried to position other points in such a way that they would cover the entire area, form a grid-like layout, and could all be visited within one day on foot or by bicycle.

We used a Testo 816 sound-level meter and a Lenovo K3 Note smartphone with Noisemeter app, as some recent studies have shown that the latter is the most trustworthy among Android apps (Pődör \& Révész, 2014; Murphy \& King, 2016). Noisemeter utilises the built-in microphone of the mobile device and is able to measure noise in decibels (dB). It is important to mention, however, that built-in microphones are designed for the human voice $(300-3,400 \mathrm{~Hz}, 40-60 \mathrm{~dB})$ and are not intended to be used in the place of scientific instruments. (Devices that use Automatic Gain Control will produce significant measurement errors; Santini et al., 2009.)

There were 14 main points where we took continuous half-hour measurements, using both sets of equipment, during peak and off-peak hours. For the purposes of this study, peak hours were defined as $7.00 \mathrm{am}$ to $9.30 \mathrm{am}$ and $5.00 \mathrm{pm}$ to $6 \mathrm{pm}$ on a Wednesday, and offpeak hours as $9.30 \mathrm{am}$ to $5 \mathrm{pm}$ on a Sunday. For the additional points, we measured the noise for 1 minute only during peak and off-peak hours; we used only the smartphone during peak-hours.

To assess the measurement results, it is important to note that constant noise exposure of around $30 \mathrm{~dB}$ during the night causes sleep disturbance. 30-34 dB hinders communication; $35-54 \mathrm{~dB}$ causes serious annoyance outdoors; exposure on a daily basis to $55-70 \mathrm{~dB}$ causes hearing impairment. 
To enhance the quality of the measurements, the recommendations for use of the equipment need to be taken into account: (1) the Testo User's guide recommends that the instrument should be used at least 30-50 cm far from the body; (2) In order to guarantee similar external conditions for the measurements, we completed the measurements on the same weekday (a Wednesday) for peak-hours, and on a Sunday for off-peak hours, at the end of September; (3) Measurements were taken during ideal weather conditions (wind speed must be less than $5 \mathrm{~m} / \mathrm{s}$; it must not be raining; Hungarian Decree on Noise Measurements 284/2007.) The average $\mathrm{dB}(\mathrm{A})$ was recorded in the database.

\section{$4 \quad$ Results}

We had 109 respondents, all except three of whom were local inhabitants. Almost $60 \%$ of them were women. The eldest respondent was 80 and the youngest 14 . The majority of the participants were in the age groups $21-30$ and 51-60, with just 3 in the $71-80$ age range. If we look at gender, most male respondents were aged 21-30, and females came primarily from the 50-60 age group. Most of the respondents were pedestrians (57\%); the second largest group were driving a car (23\%); $13 \%$ were riding a bike; the remainder were using public transport.

Instead of analysing the 'raw' polygons drawn by the participants, we aggregated the number of overlapping polygons into a 200 metres x 200 metres grid. We visualised noisy places with red, quiet places with green, using the bivariate colour method, so the darker the green on the map, the more people indicated that place as being quiet, and the darker the red, the more the place was identified as being noisy.

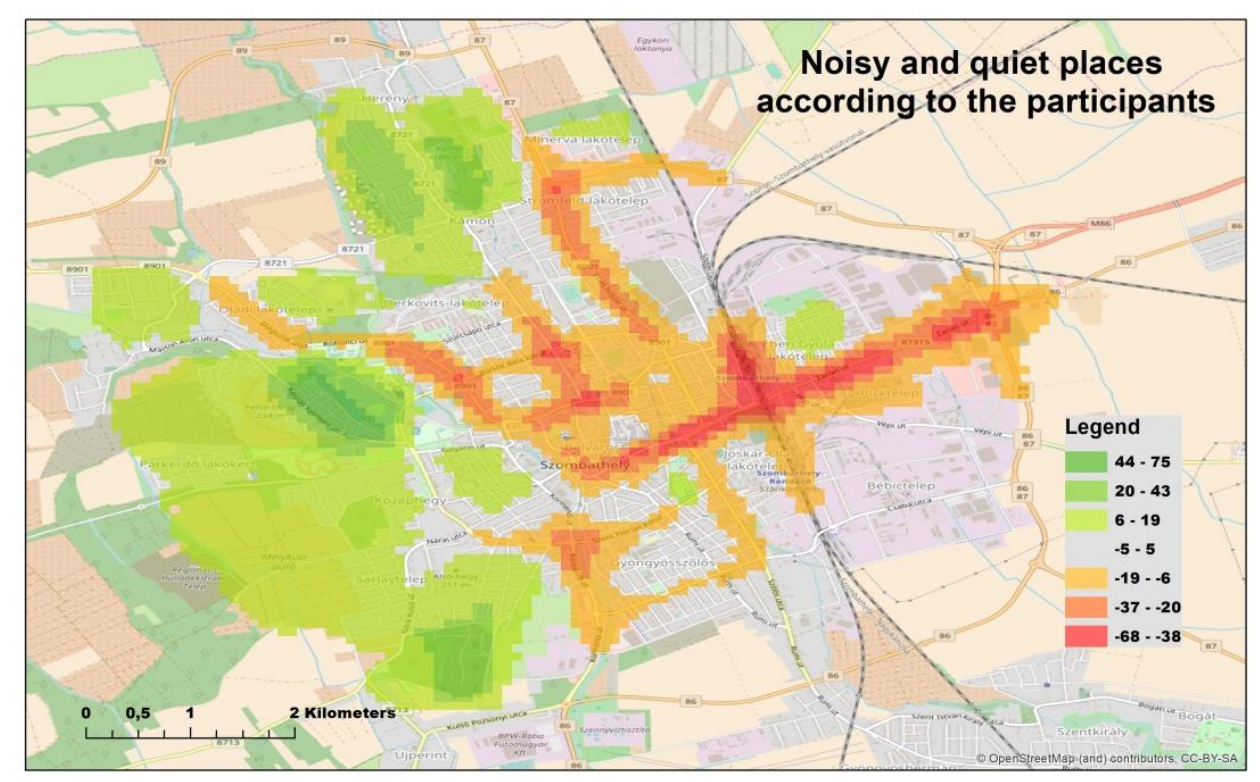

Figure 2: Maps showing the perceptions of the citizens of Szombathely for noisy (red) and quiet (green) places. 
We also investigated whether the maps of female and male participants differed. Visual interpretation of the results confirmed that female and male respondents' opinions about noisy and quiet places correlated with each other, despite the fact that, most frequently, male respondents were driving a car and females were pedestrians, and as such women were more exposed to environmental noise during their daily journey than men. We discovered a slight difference in the south-eastern part of the city, which women identified as noisy. However, this area is missing from the map of the male participants. We therefore examined the cumulated results further. The overlapping polygons for noisy places clearly correspond to the city's main road network, the areas around large shopping malls, and the area near the train station (Figure 2).

The green (i.e. quiet) places correspond to the parks, botanical garden, lake, cemetery and residential areas of the city.

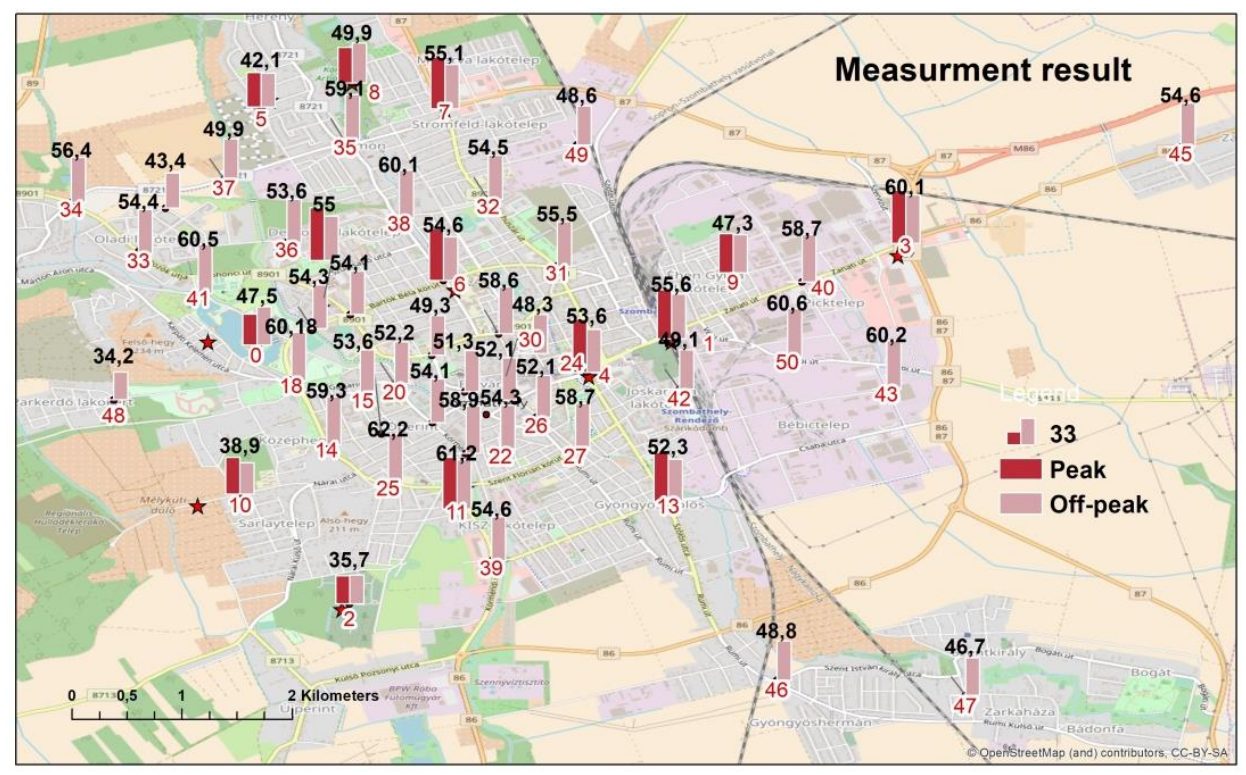

Figure 3: Map created using measurements taken by a Testo 816 sound-level meter, during peak and off-peak hours. The numbers on the map indicate the results of measurements taken during off-peak hours.

We visualised only those measurements taken using the Testo 816, as bar charts (see Figure 3). Comparing the measurements taken with the Testo sound-level meter and the Lenovo smartphone, we could not identify any significant spatial differences. During peak hours, main streets and traffic junctions produce high levels of noise, and parks and residential areas are less noisy. Industrial areas produce continuously high noise levels, both on weekdays and at the weekend. In large shopping malls, we experience high levels of noise during weekends as well as on weekdays, although $\mathrm{dB}$ values during peak hours are higher than in off-peak hours. The Pearson correlation between measurement (peak and off-peak hours, soundmeter level and smartphone) is quite high: between 0,83 and 0,94, where $\mathrm{p}<0,005$, which 
means that the correlation coefficient is statistically significant. The deviation between the mean values of peak and off-peak hours is only $4 \mathrm{~dB}$. In the case of the wood industry company, our measurement also proved the high level of noise pollution: even without heavy traffic, we measured $60 \mathrm{~dB}$ on the weekend (see Figure 3, measurement point Nr. 50).

We compared the expectations of citizens to the field measurements. As the map (Figure 2) shows, the survey participants indicated in particular main roads, areas near large shopping malls, and traffic junctions and roundabouts as being noisy. Our measurements recorded high levels of noise, of $60-66 \mathrm{~dB}$, for these areas. Participants thought that the parks, cemetery, botanical garden and lake were quiet; our control measurements showed that generally the noise level is lower in these areas: we measured 35-45 dB. However, for one measurement point at the lake we detected almost $50 \mathrm{~dB}$, and at another control point $(\mathrm{Nr}$. 48) we measured only $34 \mathrm{~dB}$. We also found other measurement points where participants' expectations of noise were higher than the reality $(\mathrm{Nr} .15,41)$. In general, they thought that there was a higher level of noise pollution in the inner city, although banning public transport has had a noticeable effect on noise levels there.

\section{Conclusion and Outlook}

The aim of this investigation was to assess the noise levels at various places in Szombathely, comparing the results of a questionnaire with actual noise measurement data.

We analysed mainly areas next to main roads and industrial locations, where the noise level is expected to be higher than the average. We also revealed the conflict between the wood industry company and the local population, whose members actively protest against environmental pollution (including the noise pollution) caused by the company.

The comparison of people's subjective opinions and the data collected on actual noise pollution has shown that in many areas the subjectively experienced and the measured noise levels overlap. This was typical in the case of heavy road traffic, as adults are highly irritated by traffic noise and consider it a significant health risk (Okokon, et al., 2015).

However, there were some places where biases occurred. This can be explained by the fact that individuals use different forms of transportation in their everyday life, which clearly influences their subjective noise-level assessment (Raw \& Griffiths, 1988). Furthermore, passing mood and sensitivity can also affect people's perception of noise (Waye \& Öhrström, 2002). As Okokon et al. (2015) have stated, traffic noise is annoying for adults, but the same level of noise near places such as the lake mentioned above does not produce similar levels of irritation, and so is not marked on the map as a noisy place.

In summary, inhabitants' opinions play an obvious and increasing role in protecting the environment. Recent studies confirm that, in general, people have a good understanding of the state of their environment. But we should note that sometimes preconceptions play a role in forming their opinions (Haklay, 2012), as in the case of the lake, which they wrongly assumed to be a quiet place. 
This type of online public survey can help municipalities to understand how citizens perceive environmental problems and to involve them in the assessment of their living space (Becker et al., 2013), giving them a sense of responsibility for the environment and enabling them to participate in further environmental decisions.

\section{References}

Becker M, Caminiti S, Fiorella D, Francis L, Gravino P, et al. (2013). Awareness and Learning in Participatory Noise Sensing. PLoS ONE 8(12): e81638. doi: 10.1371/journal.pone.0081638

Bencsics A. (2006). Noise and vibration protection in Hungarian

http://ittkesz.regiofokusz.hu/tananyagok/telepulesfejl/6_modul.pdf in Hungarian [Accessed 01.12.2017]

Boschmann, E. E., \& Cubbon, E. (2014). Sketch maps and qualitative GIS: Using cartographies of individual spatial narratives in geographic research. The Professional Geographer, 66(2), 236-248

European Environmental Agency [EEA] (2013). Environment and human health. Joint EEA-JRC report. http://www.eea.europa.eu/publications/environment-and-human-health [Accessed 01.09.2017]

Haklay, M. (2012). Citizen Science and Volunteered Geographic Information - overview and typology of participation. In Sui, D.Z., Elwood, S. \& M.F. Goodchild (Eds.), Crowdsourcing Geographic Knowledge: Volunteered Geographic Information (VGI) in Theory and Practice. Berlin, Springer. 105-122. DOI: 10.1007/978-94-007-4587-2_7

Hungarian Government Decree 280/2004. (X.20) Retrieved

from: https://net.jogtar.hu/jr/gen/hjegy_doc.cgi?docid=a0400280.kor [Accessed 01.09.2017;

in Hungarian]

Hungarian Decree on Noise measurements. Government Decree No. 284/2007.

Integrated urban development plan of Szombathely. Retrieved from: http://m.szombathely.hu/onkormanyzat/koncepciok-tervek/telepulesfejlesztes/

[Accessed 01.09.2017; in Hungarian]

Letenyei, L. (2005). Preparing mental maps. In: Letenyei László, Településkutatás I, 147-185. Budapest: Ráció. [in Hungarian]

Milgram, S. (1992): Psychological maps of Paris. In: J. Sabini \& M. Silver (Eds.), The Individual in a Social World: Essays and Experiments. New York: McGraw-Hill.

Murphy, E., \& King, E. A. (2016). Testing the accuracy of smartphones and sound level meter applications for measuring environmental noise. Applied Acoustics, 106, 16-22

Okokon, E. O., Turunen, A. W., Ung-Lanki, S., Vartiainen, A. K., Tiittanen, P., \& Lanki, T. (2015). Road-traffic noise: annoyance, risk perception, and noise sensitivity in the Finnish adult population. International Journal of Environmental Research and Public Health, 12(6), 5712-5734

Pánek, J. (2016). From Mental Maps to GeoParticipation. The Cartographic Journal, 53:4, 300-307, DOI: $10.1080 / 00087041.2016 .1243862$

Pődör A. \& Dobos, M. (2014). Official crime statistics versus fear of crime of the citizens in a Hungarian small town. In: R. Vogler, A. Car, J. Strobl \& G. Griesebner (Eds.), GI_Forum 2014 Geospatial Innovation for Society. Berlin: Herbert Wichmann. pp. 272-275

Pődör A., \& Révész. A. (2014). Noise map: professional versus crowdsourced data. In Huerta, J., Schade S., Granell C. (Eds) Proceedings of the 17th AGILE International Conference on Geographic Information Science, Castellón, Spain

Pődör, A. Révész, A., Ócsai A.,Ladomerszki Z.(2015). Testing some Aspects of Usability of Crowdsourced Smartphone Generated Noise Maps, In: Adrijana Car, Gerald Griesebner, Josef 
Strobl, Thomas Jekel (Eds.) GI_Forum 2015 - Geospatial Minds for Society. Salzburg: Universität Salzburg, 2015. p. 354. (ISBN 978-3-87907-558-4)

Pődör, A., Révész, A., Rácskai, P., \& Sasvár, Z. (2016). Measuring Citizens’ Fear of Crime Using a Web Application: A Case Study. GI_Forum 2016, 2, 123-133

Raw, G. J., \& Griffiths, I. D. (1988). Individual differences in response to road traffic noise. Journal of Sound and Vibration, 121(3), 463-471

Santini S, Ostermaier B., \& Adelmann R. (2009). On the Use of Sensor Nodes and Mobile Phones for the Assessment of Noise Pollution Levels in Urban Environments, Sixth International Conference on Networked Sensing Systems (17-19 June 2009, Pittsburgh, PA, USA), IEEE, 31-38

Szombathely Transport Consortium. (March 2015). Establishment of an intermodal communal transport hub of Szombathely. Detailed feasibility study KÖZOP- 5.5.0-09-11-2012-0017. [In Hungarian]

Testo 816 Sound Meter User's Guide https://media.testo.com/media/45/02/.../testo-816-1Instruction-Manual.pd [Accessed 01.09.2017]

Waye, K. P., \& Öhrström, E. (2002). Psycho-acoustic characters of relevance for annoyance of wind turbine noise. Journal of Sound and Vibration, 250(1), 65-73 